\title{
End-inspiratory pause prolongation in acute respiratory distress syndrome patients: effects on gas exchange and mechanics
}

\author{
Hernan Aguirre-Bermeo ', Indalecio Morán' ${ }^{1}$, Maurizio Bottiroli², Stefano Italiano ${ }^{1}$, Francisco José Parrilla', \\ Eugenia Plazolles ${ }^{1}$, Ferran Roche-Campo ${ }^{3}$ and Jordi Mancebo ${ }^{1 *}$
}

\begin{abstract}
Background: End-inspiratory pause (EIP) prolongation decreases dead space-to-tidal volume ratio $(\mathrm{Vd} / \mathrm{Vt})$ and $\mathrm{PaCO}_{2}$. We do not know the physiological benefits of this approach to improve respiratory system mechanics in acute respiratory distress syndrome (ARDS) patients when mild hypercapnia is of no concern.

Methods: The investigation was conducted in an intensive care unit of a university hospital, and 13 ARDS patients were included. The study was designed in three phases. First phase, baseline measurements were taken. Second phase, the EIP was prolonged until one of the following was achieved: (1) EIP of $0.7 \mathrm{~s}$; (2) intrinsic positive endexpiratory pressure $\geq 1 \mathrm{cmH}_{2} \mathrm{O}$; or (3) inspiratory-expiratory ratio 1:1. Third phase, the Vt was decreased (30 $\mathrm{mL}$ every 30 min) until $\mathrm{PaCO}_{2}$ equal to baseline was reached. $\mathrm{FiO}_{2}$, $\mathrm{PEEP}$, airflow and respiratory rate were kept constant.

Results: EIP was prolonged from $0.12 \pm 0.04$ to $0.7 \mathrm{~s}$ in all patients. This decreased the $\mathrm{Vd} / \mathrm{Vt}$ and $\mathrm{PaCO}_{2}(0.70 \pm 0.07$ to $0.64 \pm 0.08, p<0.001$ and $54 \pm 9$ to $50 \pm 8 \mathrm{mmHg}, p=0.001$, respectively). In the third phase, the decrease in Vt (from $6.3 \pm 0.8$ to $5.6 \pm 0.8 \mathrm{~mL} / \mathrm{Kg} \mathrm{PBW}, p<0.001$ ) allowed to decrease plateau pressure and driving pressure ( $24 \pm 3$ to $22 \pm 3 \mathrm{cmH}_{2} \mathrm{O}, p<0.001$ and $13.4 \pm 3.6$ to $10.9 \pm 3.1 \mathrm{cmH}_{2} \mathrm{O}, p<0.001$, respectively) and increased respiratory system compliance from $29 \pm 9$ to $32 \pm 11 \mathrm{~mL} / \mathrm{cmH}_{2} \mathrm{O}(p=0.001)$. $\mathrm{PaO}_{2}$ did not significantly change.

Conclusions: Prolonging EIP allowed a significant decrease in Vt without changes in $\mathrm{PaCO}_{2}$ in passively ventilated ARDS patients. This produced a significant decrease in plateau pressure and driving pressure and significantly increased respiratory system compliance, which suggests less overdistension and less dynamic strain.
\end{abstract}

Keywords: End-inspiratory pause, Dead space, Tidal volume, Acute respiratory distress syndrome, Mechanical ventilation

\section{Background}

Mechanical ventilation in patients with acute respiratory distress syndrome (ARDS) must combine both low tidal volumes $(\mathrm{Vt})$ and adequate positive end-expiratory pressure (PEEP) $[1,2]$. However, in patients with ARDS, respiratory acidosis and high airway plateau pressures $\left(P_{\text {plat }}\right)$ may limit management of ventilatory adjustments. In particular, the functional consequences of hypercapnia

\footnotetext{
*Correspondence: jmancebo@santpau.cat

${ }^{1}$ Servei de Medicina Intensiva, Hospital de la Santa Creu i Sant Pau, Universidad Autònoma de Barcelona (UAB), Sant Quintí, 89, 08041 Barcelona, Spain

Full list of author information is available at the end of the article
}

and respiratory acidosis may differ considerably depending on a patient's condition, and they may involve almost any physiological function [3-6].

Optimization of mechanical ventilation parameters is associated with a reduction in dead space and is a useful strategy to reduce hypercapnia in ARDS patients [7]. Many other strategies have also been developed to decrease hypercapnia at the bedside, such as increases in respiratory rate [8], use of active humidifiers [9] and the tracheal gas insufflation [10] or aspiration of dead space [11]. At bedside, the dead space could be calculated using the Enghoff modification of the Bohr equation. The use of this equation implies the use of $\mathrm{PaCO}_{2}$ as surrogate for 
alveolar carbon dioxide. Therefore, this equation measures a global index of efficiency of gas exchange because it takes also shunt effect into account [12].

Some authors have also shown that prolonging the end-inspiratory pause (EIP) is a feasible maneuver to achieve similar targets $[13,14]$. In experimental models [15] and in ARDS patients [14, 16-18], EIP prolongation has proven effective at enhancing $\mathrm{CO}_{2}$ elimination and decreasing partial pressure of carbon dioxide in arterial blood $\left(\mathrm{PaCO}_{2}\right)$ and also physiological dead space $\left(\mathrm{Vd}_{\text {phys }}\right)$. Prolonging EIP extends the time available for an enhanced diffusion between inhaled $\mathrm{Vt}$ and resident alveolar gas, thus facilitating the transfer of $\mathrm{CO}_{2}$ from alveoli toward the airways $[17,18]$.

Although several of the physiological studies described above have reported that EIP prolongation improves gas exchange, none have investigated the potential physiological benefits of this approach in terms of Vt reduction or improved respiratory system mechanics when hypercapnia is of no concern. To address this gap, the objective of our study was to ascertain whether EIP prolongation decreases $\mathrm{PaCO}_{2}$ and whether this effect can be used to decrease Vt while keeping $\mathrm{PaCO}_{2}$ constant. We hypothesized that this approach may have beneficial effects on respiratory system mechanics in ARDS patients.

\section{Methods}

The study was performed in the Intensive Care Unit at Hospital de la Santa Creu i Sant Pau, Barcelona (Spain). The institutional ethics committee approved the study (Reference: 10/089), and the patients' relatives gave signed informed consent.

\section{Patients}

Fourteen patients who met the criteria for ARDS [19] were included in the study. Exclusion criteria were: age $<18$ years, pregnancy, hemodynamic or respiratory instability, and variation of more than $0.5{ }^{\circ} \mathrm{C}$ in body temperature in the last $12 \mathrm{~h}$ before the study was planned [20]. One patient was excluded during the study period (see Results).

All patients were under sedation and analgesia with intravenous perfusion of midazolam and opiates. Neuromuscular blockade was used in all patients to prevent triggering of the ventilator. Careful endotracheal suctioning was performed before the protocol was started. Heated humidifiers (Fisher \& Paykel; MR 290 chamber and MR 850 ALU electric heater; Panmure, New Zealand) were used for airway humidification in all patients. These humidifiers were placed in the inspiratory limb of the circuit in accordance with the manufacturer's recommendations. The respiratory rate, $\mathrm{FiO}_{2}$, inspiratory flow (square pattern) and PEEP were kept constant throughout the study.

\section{Protocol}

All patients were in steady state in the 60 -min preceding data recording, and all of them were in a semirecumbent position. The study was performed in three consecutive 30-min phases. Measurements in the first phase (baseline phase) were taken under the mechanical ventilation parameters set by the patient's attending physician. In the second phase (EIP prolongation phase), the EIP was prolonged until one of the following parameters was reached: (1) EIP of $0.7 \mathrm{~s}$; (2) intrinsic positive end-expiratory pressure (PEEPi) $\geq 1 \mathrm{cmH}_{2} \mathrm{O}$; or (3) inspiratory-expiratory ratio $(\mathrm{I} / \mathrm{E})$ of $1: 1$. We chose the EIP prolongation time $(0.7 \mathrm{~s})$ based on findings from a previous study by Devaquet et al. [18] in which a $20 \%$ prolongation of the inspiratory time induced a significant decrease in $\mathrm{PaCO}_{2}$ and dead space. In the third phase (Vt reduction phase), the Vt was diminished in steps of $30 \mathrm{~mL}$ every $30 \mathrm{~min}$ until $\mathrm{PaCO}_{2}$ reached baseline levels.

The following data were collected at inclusion: demographic variables (age, sex, height), simplified acute physiology score II, ARDS etiology and days of mechanical ventilation.

During the last minute of each phase, we collected the following respiratory variables: peak airway pressure, Pplat, mean airway pressure, PEEPi, PEEP, driving airway pressure $(\Delta \mathrm{Paw}), \mathrm{Vt}$, dead space-to-Vt ratio $(\mathrm{Vd} / \mathrm{Vt})$, static compliance of the respiratory system (Crs) and airway resistance. At the same time, we recorded the following gas exchange variables: $\mathrm{pH}$, partial pressure of arterial oxygen $\left(\mathrm{PaO}_{2}\right), \mathrm{PaCO}_{2}$ and end-tidal carbon dioxide concentration in the mixed expired gas $\left(\mathrm{EtCO}_{2}\right)$. PEEPi was measured with a prolonged end-expiratory pause of $4 \mathrm{~s}$, performed using the ventilator expiratory hold button. $\mathrm{EtCO}_{2}$ was measured continuously with a $\mathrm{CO}_{2}$ mainstream sensor (General Electric Capnostat, Milwaukee, WI, USA). The mean value of the last 10 recorded $\mathrm{EtCO}_{2}$ values in each phase of the study was used for analysis.

Ventilatory settings and airway pressures were recorded directly from the ventilator monitoring system. Plateau pressure was measured during an endinspiratory pause. Dead space was calculated using the Enghoff modification of the Bohr equation [21]: $\mathrm{Vd} /$ $\mathrm{Vt}=\left(\mathrm{PaCO}_{2}-\mathrm{PeCO}_{2}\right) / \mathrm{PaCO}_{2}$, being $\mathrm{PeCO}_{2}$ the partial pressure of carbon dioxide in mixed expired gas. Expired gas was measured by collecting gas for $3 \mathrm{~min}$ with a Douglas bag (P-341-60; Warren E. Collins Inc., Boston, MA, USA) attached directly to the expiratory port of the ventilator. An automated analyzer (ABL 520; Radiometer A/S, Copenhagen, Denmark) was used to measure expired and arterial gases. Dead space data 
were expressed as physiological dead space $\left(\mathrm{Vd}_{\mathrm{phys}}\right.$ in $\mathrm{mL}$ ), defined as the sum of instrumental, anatomic and alveolar dead space [22]. Driving pressure $\left(\mathrm{cmH}_{2} \mathrm{O}\right)$ was calculated as Pplat-PEEP. Crs $\left(\mathrm{mL} / \mathrm{cmH}_{2} \mathrm{O}\right)$ was calculated as $\mathrm{Vt} /[$ Pplat-(PEEP + PEEPi)], and airway resistance $\left(\mathrm{cmH}_{2} \mathrm{O} / \mathrm{L} / \mathrm{s}\right)$ was calculated as (peak airway pressure - plateau pressure)/Flow. Predicted body weight (PBW) was calculated as follows: $50+0.91$ (height in $\mathrm{cm}-152.4$ ) for men and $45.5+0.91$ (height in $\mathrm{cm}-152.4$ ) for women [8]. Arterial to end-tidal $\mathrm{CO}_{2}$ gradient $(\mathrm{P}(\mathrm{a}-\mathrm{et})$ $\mathrm{CO}_{2}$ ) was calculated in each study phase. We used Puri$\tan$ Bennett $^{\mathrm{TM}} 840$ (Covidien, Galway, Ireland) and Dräger Evita XL (Dräger Medical, Lübeck, Germany) ventilators. All the ventilators used have a compressible volume compensation system.

\section{Statistical analysis}

Data are expressed as mean \pm standard deviation. The results were analyzed using one-way analysis of variance for repeated measures (ANOVA) with the GreenhouseGeisser correction. We performed the KolmogorovSmirnov test to confirm normal data distribution. Since the distribution of the data was normal, we used the Student's $t$ test and the Pearson linear correlation to compare data and correlations between phases and variables, respectively. A two-tailed $p$ value less than 0.05 was considered statistically significant. The SPSS ${ }^{\circledR}$ Statistics (version 20.0, Chicago, IL, USA) statistical software was used for statistical analysis.

\section{Results}

One of the 14 patients enrolled in the study was excluded from the analysis due to fever, tachypnea and unstable $\mathrm{EtCO}_{2}$ during the second phase of the study. The study was performed $5 \pm 4$ days after starting mechanical ventilation. Table 1 shows demographic data at admission, ARDS etiology and baseline characteristics at study day.

Baseline EIP was $0.12 \pm 0.04 \mathrm{~s}$, and it was increased to $0.7 \pm 0 \mathrm{~s}$ in all patients $(p<0.001)$. This EIP change was performed maintaining PEEPi $<1 \mathrm{cmH}_{2} \mathrm{O}(0.2 \pm 0.2$ to $\left.0.5 \pm 0.4 \mathrm{cmH}_{2} \mathrm{O}, p=0.06\right)$ and without the $\mathrm{I} / \mathrm{E}$ inverse ratio ventilation $(1: 4.7 \pm 0: 1.3$ to $1: 1.7 \pm 0: 0.4$, $p=<0.001)$. EIP prolongation decreased $\mathrm{Vd}_{\text {phys }}$ and $\mathrm{PaCO}_{2}$ significantly with respect to basal conditions (267 \pm 71 to $244 \pm 65 \mathrm{~mL}$ and $54 \pm 9$ to $50 \pm 8 \mathrm{mmHg}$, respectively; $p<0.001$ for both comparisons). The decrease in $\mathrm{PaCO}_{2}$ levels due to EIP prolongation was correlated with the drop in $\mathrm{Vd}_{\text {phys }}(r=0.871 ; p<0.001)$. Individual changes in $\mathrm{PaCO}_{2}$ and in $\mathrm{Vd}_{\text {phys }}$ are shown in Figs. 1 and 2, respectively.

Between the first and second phase, significant decreases were observed in both the $\mathrm{Vd} / \mathrm{Vt}$ ratio $(0.70 \pm 0.07$ to $0.64 \pm 0.08 ; p<0.001)$ and $\mathrm{EtCO}_{2}(41 \pm 6$ to $39 \pm 6 \mathrm{mmHg} ; p=0.006)$. Basal $\mathrm{Vd}_{\text {phys }}$ and $\mathrm{P}(\mathrm{a}$-et) $\mathrm{CO}_{2}$ had a close correlation $(r=0.75 ; p=0.003)$. The change in $\mathrm{Vd}_{\text {phys }}$ and the change in $\mathrm{P}(\mathrm{a}$-et $) \mathrm{CO}_{2}$ between the first and second phase also showed a close correlation $(r=0.68 ; p=0.001)$.

In the third phase (EIP prolongation and Vt reduction), the $\mathrm{Vt}$ was significantly reduced as compared to previous phases $(6.3 \pm 0.8$ to $5.6 \pm 0.8 \mathrm{~mL} / \mathrm{Kg}$ PBW; $p<0.001)$. In the third phase, as per protocol design, the $\mathrm{PaCO}_{2}$ and $\mathrm{pH}$ values were statistically identical to those at baseline ( $54 \pm 9$ vs. $54 \pm 10 \mathrm{mmHg} ; p=0.90$ and $7.31 \pm 0.07$ vs. $7.31 \pm 0.08 ; p=0.90$, respectively).

The $\mathrm{Vd}_{\text {phys }}$ decreased progressively and significantly during all phases of the study (267 \pm 71 to $244 \pm 65$ to $216 \pm 58 \mathrm{~mL} ; p<0.001)$. The $\mathrm{Vd}_{\text {phys }}$ and $\mathrm{Vt}$ at baseline were strongly correlated $(r=0.946 ; p<0.001)$. Additionally, the Vt reduction was tightly correlated with the decrease in $\mathrm{Vd}_{\text {phys }}(r=0.894 ; p<0.001)$. Respiratory system mechanics, gas exchange, hemodynamics, and temperature data throughout the study are also given in Table 2 .

\section{Discussion}

The main finding of our study was that the end-inspiratory pause prolongation allowed to decrease tidal volume while maintaining similar $\mathrm{PaCO}_{2}$ levels. Indeed, the decrease in tidal volume led to a significant decrease in Pplat and $\Delta \mathrm{Paw}$, and it also improved the respiratory system compliance.

Several studies have shown that prolongation of EIP enhances $\mathrm{CO}_{2}$ elimination and decreases dead space and $\mathrm{PaCO}_{2}$ levels [14-18]. Diffusion of $\mathrm{CO}_{2}$ is time dependent, and EIP prolongation increases the time available for alveolar gas exchange [14, 23, 24]. Devaquet et al. [18] extended inspiratory time from $0.7 \pm 0.2$ to $1.4 \pm 0.3 \mathrm{~s}$ by increasing the inspiratory pause time from 0 to $20 \%$ of the total breathing cycle. They observed that this modification significantly decreased both $\mathrm{Vd} / \mathrm{Vt}$ (around $10 \%$ ) and $\mathrm{PaCO}_{2}$ (around $11 \%$ ). Despite these beneficial effects of prolonged EIP and the direct relationship between inspiratory time and enhanced $\mathrm{CO}_{2}$ elimination $[16,18]$, EIP prolongation may lead to potentially adverse effects such as PEEPi production and inversion of the I/E ratio together with increases in mean airway pressure. These effects might also provoke hyperinflation, thus altering cardiac performance $[25,26]$. Nevertheless, Devaquet and colleagues [18] showed that EIP could be prolonged without significantly increasing PEEPi (I/E ratio 1:1.5). Not surprisingly, and in spite of a significant increase in EIP, we did not induce any significant increase in PEEPi since the expiratory time was long enough to avoid air trapping at the end of a passive expiration (average expiratory time $1.7 \pm 0.3 \mathrm{~s}$ ). Actually (see Table 2), the average product of three time constants (the time needed to 


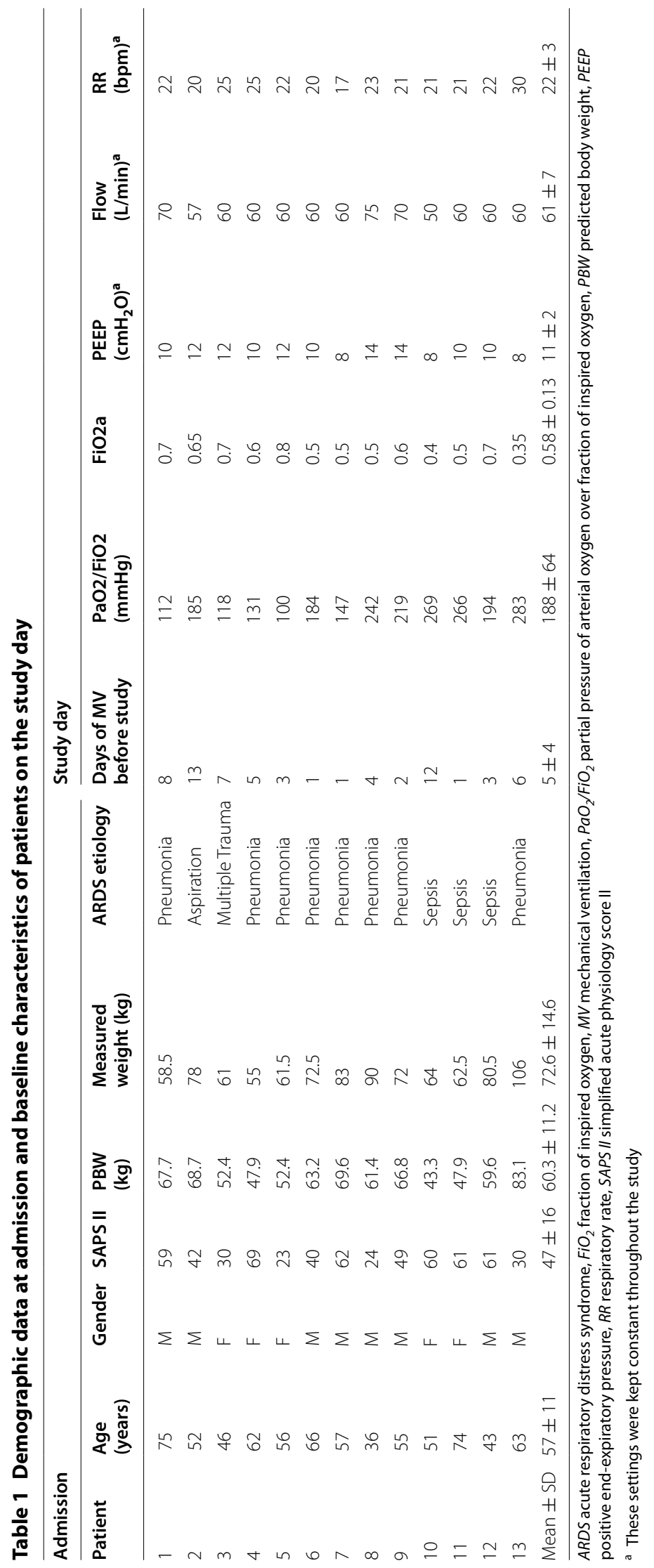




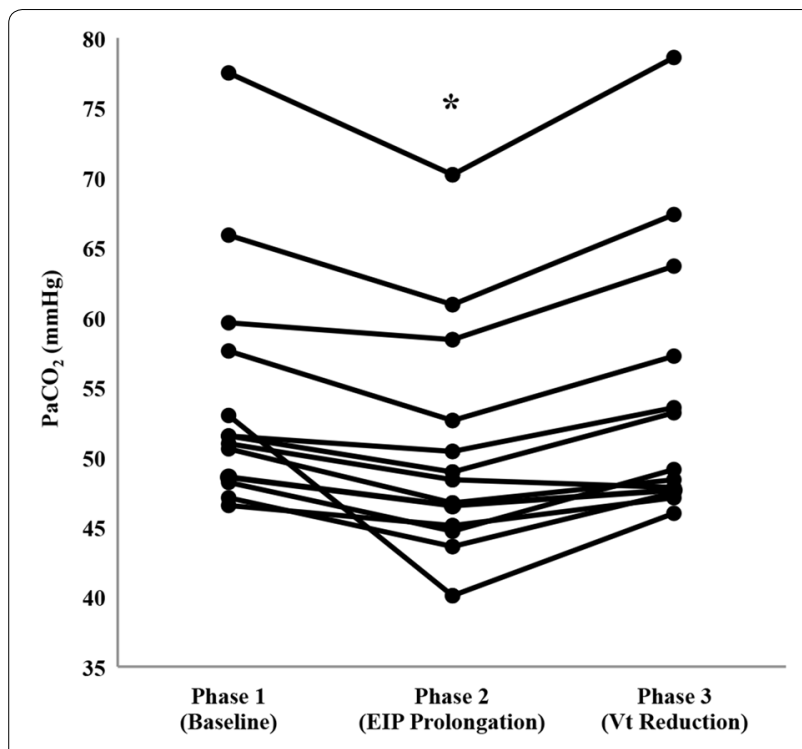

Fig. 1 Individual values for $\mathrm{PaCO}_{2}$ during the study. The asterisk denotes statistically significant differences $(p<0.001)$ during prolongation of end-inspiratory pause. EIP end-inspiratory pause, $\mathrm{PaCO}_{2}$ partial pressure of carbon dioxide in arterial blood, $V t$ tidal volume

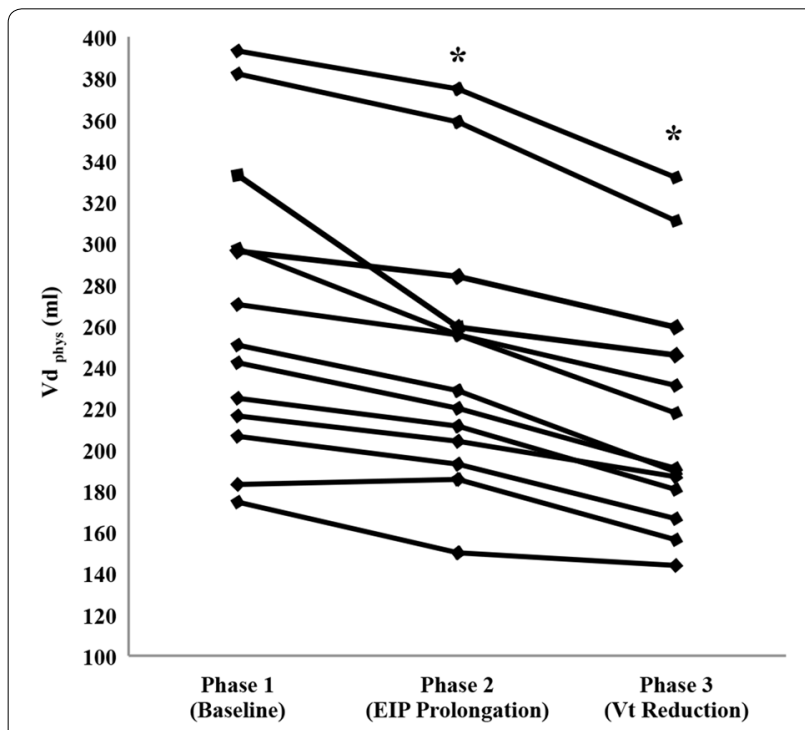

Fig. 2 Individual values for $V d_{\text {phys }}$ during the study. The asterisks denote a significant, progressive decrease in $V_{d}$ phys $(p<0.001)$ during prolongation of end-inspiratory pause (EIP) and during $\vee t$ reduction. EIP end-inspiratory pause, $V d_{\text {phys }}$ physiological dead space, $V t$ tidal volume

passively exhale $96 \%$ of inhaled tidal volume) was in our patients about $1.1 \mathrm{~s} .(0.373 \times 3=1.1 \mathrm{~s})$, well below to the average expiratory time.

Prolongation of EIP in our patients caused a significant decrease in dead space and $\mathrm{PaCO}_{2}$ levels that was similar to previously reported [14-18]. When comparing phase 1 (baseline) and phase 2 (isolated EIP prolongation), we found that the decrease in the $\mathrm{Vd} / \mathrm{Vt}$ correlated well with the drop in $\mathrm{PaCO}_{2}(r=0.810 ; p<0.001)$. These changes observed in our patients may be explained by the increase on the time available for distribution and diffusion of inspired tidal gas within resident alveolar gas during EIP prolongation [14]. Indeed, total PEEP levels, airflow, respiratory rate, tidal volume and respiratory mechanics were totally unchanged in this phase of our study $[14,27,28]$.

Comparing the second (isolated EIP prolongation) and third (EIP prolongation and Vt reduction) phases, our data showed that the $\mathrm{Vd} / \mathrm{Vt}$ ratio remained unchanged. However, the $\mathrm{Vd}_{\text {phys }}$, expressed in $\mathrm{mL}$, decreased significantly between phases 2 and 3 . This is explained by the significant reduction in $\mathrm{Vt}$ (that also provoked a decrease in $\mathrm{Vd}_{\text {phys }}$ ) during the third phase as compared to the previous phases, and thus $\mathrm{Vd} / \mathrm{Vt}$ ratio did not change. The fact that the reduction in Vt in the third phase was accompanied by a significant decrease in $\mathrm{Vd}_{\text {phys }}$ and $\Delta$ Paw (with a significant increase in compliance) suggests that some degree of overdistension might be present at baseline.

As previously described, low tidal volume ventilation in ARDS may induce hypercapnia and, secondarily, induce pulmonary artery hypertension that may impair right ventricular function [29] and eventually cause acute cor pulmonale [30]. To reduce hypercapnia in ARDS ventilated patients, active heated humidifiers are often used. These devices significantly decrease dead space, $\mathrm{PaCO}_{2}$ and ventilator mechanical load [9] without increasing airflow resistance [31]. Although active humidification is recommended over heat and moisture exchangers in ARDS patients [32], two studies focussing on the effects of EIP prolongation on gas exchange $[16,17]$ did not describe the type of humidification used in their patients. A third study used passive or active humidification (10 and 5 patients, respectively) [18]. However, the effects on $\mathrm{PaCO}_{2}$ in all these studies [16-18] were consistently the same, thus suggesting that humidification type per se does not influence the effects of EIP on $\mathrm{PaCO}_{2}$.

Another technique used to decrease hypercapnia is to increase the respiratory rate. However, in ARDS patients, several studies have shown that a high respiratory rate led to gas trapping and induced PEEPi [33, 34]. In addition, experimental models suggested that higher respiratory rates may contribute to the development of ventilatorinduced lung injury [35, 36]. Vieillard-Baron et al. [25] compared two respiratory rate strategies, 30 versus 15 breaths/min. They found that the high respiratory rate did not reduce $\mathrm{PaCO}_{2}$ levels but produced dynamic hyperinflation and reduced the cardiac index. In our patients, EIP prolongation was achieved with a relatively 
Table 2 Respiratory system mechanics, gas exchange and hemodynamic data during the study

\begin{tabular}{|c|c|c|c|c|c|}
\hline & $\begin{array}{l}\text { Phase } 1 \\
\text { (baseline) }\end{array}$ & $\begin{array}{l}\text { Phase } 2 \\
\text { (EIP prolongation) }\end{array}$ & $\begin{array}{l}\text { Phase } 3 \\
\text { (Vt reduction) }\end{array}$ & $\begin{array}{l}\text { Overall } \\
p \text { value }\end{array}$ & $\begin{array}{l}\text { Intergroup } \\
\text { differences }\end{array}$ \\
\hline $\operatorname{EIP}(s)$ & $0.12 \pm 0.04$ & $0.7 \pm 0$ & $0.7 \pm 0$ & $<0.001$ & $a, b$ \\
\hline Ppeak $\left(\mathrm{cmH}_{2} \mathrm{O}\right)$ & $38 \pm 6$ & $38 \pm 6$ & $35 \pm 5$ & $<0.001$ & $b, c$ \\
\hline Pmean $\left(\mathrm{cmH}_{2} \mathrm{O}\right)$ & $15 \pm 3$ & $18 \pm 2$ & $17 \pm 2$ & $<0.001$ & $a, b, c$ \\
\hline Pplat $\left(\mathrm{cmH}_{2} \mathrm{O}\right)$ & $24 \pm 3$ & $24 \pm 3$ & $22 \pm 3$ & $<0.001$ & $b, c$ \\
\hline PEEPi $\left(\mathrm{cmH}_{2} \mathrm{O}\right)$ & $0.2 \pm 0.2$ & $0.5 \pm 0.4$ & $0.5 \pm 0.4$ & 0.06 & \\
\hline $\mathrm{Vt}(\mathrm{mL})$ & $378 \pm 73$ & $378 \pm 73$ & $336 \pm 61$ & $<0.001$ & $b, c$ \\
\hline Vt (PBW; mL/Kg) & $6.3 \pm 0.8$ & $6.3 \pm 0.8$ & $5.6 \pm 0.8$ & $<0.001$ & $b, c$ \\
\hline$V d_{\text {phys }}(m L)$ & $267 \pm 71$ & $244 \pm 65$ & $216 \pm 58$ & $<0.001$ & $a, b, c$ \\
\hline $\mathrm{Vd} / \mathrm{Vt}$ & $0.70 \pm 0.07$ & $0.64 \pm 0.08$ & $0.64 \pm 0.08$ & $<0.001$ & $a, b$ \\
\hline $\mathrm{Crs}\left(\mathrm{mL} / \mathrm{cmH}_{2} \mathrm{O}\right)$ & $29 \pm 9$ & $29 \pm 9$ & $32 \pm 11$ & 0.001 & $b, c$ \\
\hline$\triangle \operatorname{Paw}\left(\mathrm{cmH}_{2} \mathrm{O}\right)$ & $13.6 \pm 3.6$ & $13.4 \pm 3.6$ & $10.9 \pm 3.1$ & $<0.001$ & $a, b, c$ \\
\hline $\mathrm{R}_{\mathrm{aw}}\left(\mathrm{cmH}_{2} \mathrm{O} / \mathrm{L} / \mathrm{s}\right)$ & $14 \pm 5$ & $13 \pm 5$ & $13 \pm 4$ & 0.28 & \\
\hline $\mathrm{pH}$ & $7.31 \pm 0.07$ & $7.34 \pm 0.09$ & $7.31 \pm 0.08$ & $<0.001$ & $a, c$ \\
\hline $\mathrm{PaO}_{2}(\mathrm{mmHg})$ & $102 \pm 23$ & $98 \pm 23$ & $105 \pm 29$ & 0.35 & \\
\hline $\mathrm{PaCO}_{2}(\mathrm{mmHg})$ & $54 \pm 9$ & $50 \pm 8$ & $54 \pm 10$ & $<0.001$ & $a, c$ \\
\hline $\mathrm{EtCO}_{2}(\mathrm{mmHg})$ & $41 \pm 6$ & $39 \pm 6$ & $43 \pm 7$ & 0.002 & $a, c$ \\
\hline $\mathrm{P}$ (a-et) $\mathrm{CO}_{2}(\mathrm{mmHg})$ & $13 \pm 6$ & $12 \pm 8$ & $12 \pm 9$ & 0.27 & \\
\hline MAP $(\mathrm{mmHg})$ & $80 \pm 12$ & $76 \pm 9$ & $77 \pm 12$ & 0.08 & \\
\hline HR (beats/min) & $87 \pm 19$ & $83 \pm 20$ & $86 \pm 21$ & 0.14 & \\
\hline Temperature $\left({ }^{\circ} \mathrm{C}\right)$ & $36.7 \pm 0.9$ & $36.7 \pm 0.9$ & $36.6 \pm 0.8$ & 0.61 & \\
\hline
\end{tabular}

Data are presented as number (\%) or mean \pm SD

Intergroup differences $(p<0.05)$ : a, phase 1 versus phase 2 ; b, phase 1 versus phase $3 ; c$, phase 2 versus phase 3

Crs static compliance of the respiratory system, EIP end-inspiratory pause, $\mathrm{EtCO}_{2}$ end-tidal carbon dioxide concentration in the expired air, $\mathrm{FiO} \mathrm{f}_{2}$ fraction of inspired oxygen, $\mathrm{HR}$ heart rate, $M A P$ mean arterial pressure, $\mathrm{PaO}_{2}$ partial pressure of oxygen in arterial blood, $\mathrm{PaCO}$, partial pressure of carbon dioxide in arterial blood, $P B W$ predicted body weight, $P E E P i$ intrinsic positive end-expiratory pressure, Pmean mean airway pressure, Ppeak peak airway pressure, $P$ plat plateau airway pressure, $\mathrm{P}$ (a-et) $\mathrm{CO}_{2}$ arterial to end-tidal $\mathrm{CO}_{2}$ gradient, Raw airway resistance, $V d_{\text {phys }}$ physiological dead space, $V d / V t$ dead space-to-Vt ratio, $V t$ tidal volume, $\Delta P a w$ driving airway pressure

high inspiratory flow rate $(1 \mathrm{~L} / \mathrm{s})$, thus avoiding inverse I/E ratio. This was a safe strategy to decrease $\mathrm{PaCO}_{2}$ levels, while keeping respiratory rate constant (22 breaths/ min) and not generating PEEPi.

In our study, the reduction in Vt to maintain isocapnia was modest. Should major reductions in Vt were required, then the use of invasive extracorporeal carbon dioxide removal devices had to be considered in order to avoid acute hypercapnia [37].

Studies analyzing the EIP prolongation did not describe changes in $\mathrm{PaO}_{2}[14,18]$, except one study by Mercat et al. [16]. This latter study found a slight, but not statistically significant, increase in $\mathrm{PaO}_{2}$ levels during EIP prolongation. This finding was not confirmed in our study. We speculate that the length of time that patients are maintained with EIP prolongation and the mean airway pressure achieved during extended EIP may have contributed to this finding. Indeed, in Mercat's study [16], EIP prolongation was continued for $1 \mathrm{~h}$ with a mean airway pressure of $21 \mathrm{cmH}_{2} \mathrm{O}$ and an $\mathrm{I} / \mathrm{E}$ ratio 1.1. In contrast, in Devaquet's study [18] and in our own study, EIP prolongation was shorter (30 $\mathrm{min}$ in both), mean airway pressure was lower ( 15 and $17 \mathrm{cmH}_{2} \mathrm{O}$, respectively), and the $\mathrm{I} / \mathrm{E}$ ratios achieved were 1:1.5 in Devaquet's study and 1:1.7 in ours.

The main novelty of our study is that prolonging EIP allowed to reduce Vt by $11 \%$ (from $6.3 \pm 0.8$ to $5.6 \pm 0.8 \mathrm{~mL} / \mathrm{kg}$ of PBW; $p<0.001$ ), maintaining $\mathrm{PaCO}_{2}$ levels equal to baseline. These sequential ventilatory changes were accompanied by a reduction in $\mathrm{Vd}_{\text {phys }}$. Also, when $\mathrm{PaCO}_{2}$ returned to baseline due to a reduction in Vt, we found a significant decrease in Pplat and an increase in Crs. In addition, these changes in ventilatory mechanics were accompanied by a significant decrease in $\Delta$ Paw. All those findings could be explained by a degree of baseline overinflation even though our initial Vt was low [38]. We further support our contention by the tight correlation between $\mathrm{Vt}$ and $\mathrm{Vd}_{\text {phys }}$ at the onset of the study and the tight correlation between the decrease in $\mathrm{Vt}$ and $\mathrm{Vd}_{\text {phys }}$ at the end of the study. Our patients were basally ventilated with parameters similar to those used in previous studies [16-18] in terms of Vt and PEEP, and 
$\mathrm{Vd} / \mathrm{Vt}$ was also similar. Moreover, in our patients, Crs was lower $\left(29 \mathrm{~mL} / \mathrm{cmH}_{2} \mathrm{O}\right)$ than in Mercat and Devaquet studies (37 and $50 \mathrm{~mL} / \mathrm{cmH}_{2} \mathrm{O}$, respectively). Our findings thus suggest that if $\mathrm{PaCO}_{2}$ is clinically tolerable, EIP prolongation in ARDS provides physiological benefits including a small and consistent decrease in Vt which may help decrease dynamic strain [39].

In our study, a slight but not statistically significant decrease in mean arterial pressure was observed. Such trend could have been the result of complex interactions of $\mathrm{PaCO}_{2}$ and mean airway pressure in cardiovascular system.

We think that EIP prolongation is a feasible maneuver to optimize the consequences of mechanical ventilation in ARDS patients. Physicians may consider using an EIP prolongation in the early phase of ARDS when patients often require sedation and neuromuscular blocking agents. In our study, we have effectively implemented this strategy by using active humidification, relatively high inspiratory flow rates and close monitoring of PEEPi. This bundle decreases $\mathrm{PaCO}_{2}$, which in turn will allow to further decrease $\mathrm{Vt}$ and the consequent lung strain when isocapnic conditions are met.

One of the limitations of our study is the relatively small number of patients, the majority with pneumonia, and the fact that the study is short term. Studies with patients with different ARDS etiologies and larger numbers are warranted to confirm our data. Also, we did not measure other parameters such as inflammatory mediators or lung volumes. The calculation of dead space using the Enghoff modification of Bohr equation in patients with large shunt fractions $(>20-30 \%)$ could underestimate dead space fraction [12]. In our study, we did not measure intrapulmonary shunt. However, according to the gas exchange values that we obtained, shunt fractions above $30 \%$ are unlikely. Additionally, the EIP prolongation increases the mechanical inflation time and it could extend into neural expiration. Asynchronies may thus develop and cause an inadequate patient-ventilator interaction when the patients are not paralyzed [39-41]. Our results could be dependent on our routine management of mechanical ventilation in ARDS patients, but our findings have been consistent in all patients and we consider they could be extrapolated to other ARDS patients. Finally, the absolute decrease in tidal volume, although statistically significant, is moderate.

\section{Conclusions}

In conclusion, our data indicate that EIP prolongation is a simple and feasible strategy to decrease dead space and $\mathrm{PaCO}_{2}$ levels. In addition, when $\mathrm{PaCO}_{2}$ levels are of no clinical concern, EIP prolongation allows us to further decrease tidal volume. This, in turn, decreases plateau airway pressure, driving airway pressure and improves respiratory system compliance, suggesting less overdistension and less risk of dynamic strain and lung injury. Therefore, the use of this simple ventilator maneuver during mechanical ventilation in sedated and paralyzed ARDS patients merits consideration.

\section{Abbreviations}

ARDS: acute respiratory distress syndrome; $\mathrm{Crs}$ : static compliance of the respiratory system; EIP: end-inspiratory pause; $\mathrm{EtCO}_{2}$ : end-tidal carbon dioxide concentration in the mixed expired gas; IE: inspiratory-expiratory ratio; $\mathrm{PaCO}_{2}$ : partial pressure of carbon dioxide in arterial blood; $\mathrm{PaO}_{2}$ : partial pressure of arterial oxygen; PBW: predicted body weight; $\mathrm{PeCO}_{2}$ : partial pressure of carbon dioxide in mixed expired gas; PEEP: positive end-expiratory pressure; PEEPi: intrinsic positive end-expiratory pressure; $P_{\text {plat: }}$ : plateau airway pressure; $P$ (a-et) $\mathrm{CO}_{2}$ : arterial to end-tidal $\mathrm{CO}_{2}$ gradient; $\mathrm{Vd} / \mathrm{Vt}$ : dead space-to- $\mathrm{Vt}$ ratio; $\mathrm{Vd}_{\text {phys: }}$ : physiological dead space; $\vee$ t: tidal volume; $\triangle$ Paw: driving airway pressure.

\section{Authors' contributions}

All authors participated in the study design, data collection and analysis, manuscript writing and final approval. All authors read and approved the final manuscript.

\section{Author details}

${ }^{1}$ Servei de Medicina Intensiva, Hospital de la Santa Creu i Sant Pau, Universidad Autònoma de Barcelona (UAB), Sant Quintí, 89, 08041 Barcelona, Spain.

${ }^{2}$ Anestesia e Rianimazione 3, Ospedale Niguarda Ca' Granda, Milan, Italy.

${ }^{3}$ Servei de Medicina Intensiva, Hospital Verge de la Cinta, Tortosa, Spain.

\section{Competing interests}

The authors declare that they have no competing interests.

Received: 23 May 2016 Accepted: 11 August 2016

Published online: 24 August 2016

\section{References}

1. Eichacker PQ, Gerstenberger EP, Banks SM, Cui X, Natanson C. Metaanalysis of acute lung injury and acute respiratory distress syndrome trials testing low tidal volumes. Am J Respir Crit Care Med. 2002;166:1510-4.

2. Briel M, Meade M, Mercat A, Brower RG, Talmor D, Walter SD, Slutsky AS, Pullenayegum E, Zhou Q, Cook D, Brochard L, Richard JC, Lamontagne F, Bhatnagar N, Stewart TE, Guyatt G. Higher vs lower positive end-expiratory pressure in patients with acute lung injury and acute respiratory distress syndrome: systematic review and meta-analysis. JAMA. 2010;303:865-73.

3. Feihl F, Perret C. Permissive hypercapnia. How permissive should we be? Am J Respir Crit Care Med. 1994;150:1722-37.

4. Laffey JG, Engelberts D, Kavanagh BP. Buffering hypercapnic acidosis worsens acute lung injury. Am J Respir Crit Care Med. 2000;161:141-6.

5. Feihl F, Eckert P, Brimioulle S, Jacobs O, Schaller MD, Melot C, Naeije R. Permissive hypercapnia impairs pulmonary gas exchange in the acute respiratory distress syndrome. Am J Respir Crit Care Med. 2000;162:209-15.

6. O'Croinin DF, Nichol AD, Hopkins N, Boylan J, O'Brien S, O'Connor C, Laffey JG, McLoughlin P. Sustained hypercapnic acidosis during pulmonary infection increases bacterial load and worsens lung injury. Crit Care Med. 2008;36:2128-35.

7. Richecoeur J, Lu Q, Vieira SR, Puybasset L, Kalfon P, Coriat P, Rouby JJ. Expiratory washout versus optimization of mechanical ventilation during permissive hypercapnia in patients with severe acute respiratory distress syndrome. Am J Respir Crit Care Med. 1999;160:77-85.

8. Network The Acute Respiratory Distress Syndrome. Ventilation with lower tidal volumes as compared with traditional tidal volumes for acute lung injury and the acute respiratory distress syndrome. N Engl J Med. 2000;342:1301-8. 
9. Moran I, Bellapart J, Vari A, Mancebo J. Heat and moisture exchangers and heated humidifiers in acute lung injury/acute respiratory distress syndrome patients. Effects on respiratory mechanics and gas exchange. Intensive Care Med. 2006;32:524-31.

10. Ravenscraft SA, Burke WC, Nahum A, Adams AB, Nakos G, Marcy TW, Marini JJ. Tracheal gas insufflation augments $\mathrm{CO} 2$ clearance during mechanical ventilation. Am Rev Respir Dis. 1993;148:345-51.

11. De Robertis E, Servillo G, Tufano R, Jonson B. Aspiration of dead space allows isocapnic low tidal volume ventilation in acute lung injury. Relationships to gas exchange and mechanics. Intensive Care Med. 2001;27:1496-503.

12. Suarez-Sipmann F, Bohm SH, Tusman G. Volumetric capnography: the time has come. Curr Opin Crit Care. 2014;20:333-9.

13. Astrom E, Uttman L, Niklason L, Aboab J, Brochard L, Jonson B. Pattern of inspiratory gas delivery affects $\mathrm{CO}_{2}$ elimination in health and after acute lung injury. Intensive Care Med. 2008;34:377-84.

14. Aboab J, Niklason $L, U t t m a n ~ L$, Brochard L, Jonson B. Dead space and $\mathrm{CO}_{2}$ elimination related to pattern of inspiratory gas delivery in ARDS patients. Crit Care. 2012;16:R39.

15. Uttman $\mathrm{L}$, Jonson $\mathrm{B}$. A prolonged postinspiratory pause enhances $\mathrm{CO}_{2}$ elimination by reducing airway dead space. Clin Physiol Funct Imaging. 2003;23:252-6.

16. Mercat A, Diehl JL, Michard F, Anguel N, Teboul JL, Labrousse J, Richard C. Extending inspiratory time in acute respiratory distress syndrome. Crit Care Med. 2001;29:40-4

17. Aboab J, Niklason L, Uttman L, Kouatchet A, Brochard L, Jonson B. $\mathrm{CO}_{2}$ elimination at varying inspiratory pause in acute lung injury. Clin Physio Funct Imaging. 2007;27:2-6.

18. Devaquet J, Jonson B, Niklason L, Si Larbi AG, Uttman L, Aboab J, Brochard L. Effects of inspiratory pause on $\mathrm{CO}_{2}$ elimination and arterial $\mathrm{PCO}_{2}$ in acute lung injury. J Appl Physiol. 2008;105:1944-9.

19. Ranieri VM, Rubenfeld GD, Thompson BT, Ferguson ND, Caldwell E, Fan E, Camporota L, Slutsky AS. Acute respiratory distress syndrome: the Berlin definition. JAMA. 2012;307:2526-33.

20. Bacher A. Effects of body temperature on blood gases. Intensive Care Med. 2005;31:24-7.

21. Fletcher R, Jonson B, Cumming G, Brew J. The concept of deadspace with special reference to the single breath test for carbon dioxide. $\mathrm{Br} J$ Anaesth. 1981;53:77-88.

22. Lucangelo U, Blanch L. Dead space. Intensive Care Med. 2004;30:576-9.

23. Knelson JH, Howatt WF, DeMuth GR. Effect of respiratory pattern on alveolar gas exchange. J Appl Physiol. 1970;29:328-31.

24. Shanholtz C, Brower R. Should inverse ratio ventilation be used in adult respiratory distress syndrome? Am J Respir Crit Care Med. 1994;149:1354-8.

25. Vieillard-Baron A, Prin S, Augarde R, Desfonds P, Page B, Beauchet A, Jardin $\mathrm{F}$. Increasing respiratory rate to improve $\mathrm{CO}_{2}$ clearance during mechanical ventilation is not a panacea in acute respiratory failure. Crit Care Med. 2002;30:1407-12

26. Armstrong BW Jr, Maclntyre NR. Pressure-controlled, inverse ratio ventilation that avoids air trapping in the adult respiratory distress syndrome. Crit Care Med. 1995;23:279-85.

27. Blanch L, Fernandez R, Benito S, Mancebo J, Net A. Effect of PEEP on the arterial minus end-tidal carbon dioxide gradient. Chest. 1987;92:451-4.

28. Beydon L, Uttman L, Rawal R, Jonson B. Effects of positive end-expiratory pressure on dead space and its partitions in acute lung injury. Intensive Care Med. 2002;28:1239-45.
29. Carvalho CR, Barbas CS, Medeiros DM, Magaldi RB, Lorenzi Filho G, Kairalla RA, Deheinzelin D, Munhoz C, Kaufmann M, Ferreira M, Takagaki TY, Amato MB. Temporal hemodynamic effects of permissive hypercapnia associated with ideal PEEP in ARDS. Am J Respir Crit Care Med. 1997;156:1458-66.

30. Vieillard-Baron A, Schmitt JM, Augarde R, Fellahi JL, Prin S, Page B, Beauchet $A$, Jardin F. Acute cor pulmonale in acute respiratory distress syndrome submitted to protective ventilation: incidence, clinical implications, and prognosis. Crit Care Med. 2001;29:1551-5.

31. Moran I, Cabello B, Manero E, Mancebo J. Comparison of the effects of two humidifier systems on endotracheal tube resistance. Intensive Care Med. 2011;37:1773-9.

32. Restrepo RD, Walsh BK. Humidification during invasive and noninvasive mechanical ventilation: 2012. Respir Care. 2012;57:782-8.

33. Richard JC, Brochard L, Breton L, Aboab J, Vandelet P, Tamion F, Maggiore SM, Mercat A, Bonmarchand G. Influence of respiratory rate on gas trapping during low volume ventilation of patients with acute lung injury. Intensive Care Med. 2002;28:1078-83.

34. de Durante G, del Turco M, Rustichini L, Cosimini P, Giunta F, Hudson LD, Slutsky AS, Ranieri VM. ARDSNet lower tidal volume ventilatory strategy may generate intrinsic positive end-expiratory pressure in patients with acute respiratory distress syndrome. Am J Respir Crit Care Med. 2002;165:1271-4

35. Hotchkiss JR Jr, Blanch L, Murias G, Adams AB, Olson DA, Wangensteen $\mathrm{OD}$, Leo PH, Marini JJ. Effects of decreased respiratory frequency on ventilator-induced lung injury. Am J Respir Crit Care Med. 2000;161:463-8.

36. Conrad SA, Zhang S, Arnold TC, Scott LK, Carden DL. Protective effects of low respiratory frequency in experimental ventilator-associated lung injury. Crit Care Med. 2005;33:835-40.

37. Fanelli V, Ranieri MV, Mancebo J, Moerer O, Quintel M, Morley S, Moran I, Parrilla F, Costamagna A, Gaudiosi M, Combes A. Feasibility and safety of low-flow extracorporeal carbon dioxide removal to facilitate ultraprotective ventilation in patients with moderate acute respiratory distress sindrome. Crit Care. 2016;20:36.

38. Terragni PP, Rosboch G, Tealdi A, Corno E, Menaldo E, Davini O, Gandini G, Herrmann P, Mascia L, Quintel M, Slutsky AS, Gattinoni L, Ranieri VM. Tidal hyperinflation during low tidal volume ventilation in acute respiratory distress syndrome. Am J Respir Crit Care Med. 2007;175:160-6.

39. Mauri T, Yoshida T, Bellani G, Goligher EC, Carteaux G, Rittayamai N, Mojoli F, Chiumello D, Piquilloud L, Grasso S, Jubran A, Laghi F, Magder S, Pesenti A, Loring S, Gattinoni L, Talmor D, Blanch L, Amato M, Chen L, Brochard $\mathrm{L}$, Mancebo J. Esophageal and transpulmonary pressure in the clinical setting: meaning, usefulness and perspectives. Intensive Care Med 2016. doi:10.1007/s00134-016-4400-x.

40. Georgopoulos D. Effects of mechanical ventilation on control of breathing. In: Tobin $\mathrm{M}$, editor. Principles and practice of mechanical ventilation. New York: McGraw-Hill; 2013. p. 805-20.

41. Murias G, Lucangelo U, Blanch L. Patient-ventilator asynchrony. Curr Opin Crit Care. 2016;22:53-9.

\section{Submit your manuscript to a SpringerOpen ${ }^{\circ}$ journal and benefit from:}

- Convenient online submission

- Rigorous peer review

- Immediate publication on acceptance

- Open access: articles freely available online

- High visibility within the field

- Retaining the copyright to your article

Submit your next manuscript at $\boldsymbol{\nabla}$ springeropen.com 